\title{
A incongruência do conceito de pessoa alfabetizada da justiça eleitoral com as funções constitucionais dos representantes públicos
}

\author{
Marilza Ferreira do Nascimento ${ }^{1}$ \\ Pábula Novais de Oliveira
}

\begin{abstract}
Resumo: Trata este artigo da inelegibilidade dos analfabetos e da incompatibilidade constitucional de se deferir candidatura a analfabetos funcionais. Apresentam-se, inicialmente, alguns aspectos gerais sobre os direitos políticos e o conceito de analfabeto apresentado pela Unesco e pela Pedagogia, o qual é adotado pela Justiça Eleitoral. A seguir, sustenta-se que a interpretação dos Tribunais Eleitorais para o termo analfabeto encontra-se em dissonância com o objetivo constitucional de se estabelecer o analfabetismo como uma das causas de inelegibilidade, em razão de a condição de analfabeto funcional inviabilizar a leitura, a compreensão, a interpretação e a produção dos atos políticos, legislativos e administrativos intrínsecos às atribuições dos representantes do povo, em face da própria Constituição. O estudo parte da análise da Constituição da República, da doutrina, de leis infraconstitucionais e de resoluções e acórdãos do Tribunal Superior Eleitoral (TSE). Conclui-se, ao final, que o interesse público no efetivo exercício do mandato prevalece sobre o interesse individual ao se disputar cargo eleitoral.
\end{abstract}

Palavras-chave: Analfabeto funcional. Elegibilidade. Incompatibilidade constitucional.

\begin{abstract}
The objective of the present study is the ineligibility of illiterates and constitutional incompatibility of granting candidacy to functional illiterates. Initially some general aspects about political rights are presented, such as the concept of illiterates by Unesco and in terms of pedagogy adopted in electoral Justice. Afterwards, it is maintained that the interpretation of the Electoral Tribunal adopted to the illiterate term is in dissonance with the constitutional objective of establishing illiteracy as one of the causes of ineligibility, because the condition of functional illiterate renders unreadable, interpretation and production of legislative and administrative acts, which, in the face of the Constitution itself, are attributions expected from the representatives of the people. The study starts with the analysis of the Constitution of the Republic, of doctrine, of infraconstitutional laws and of resolutions and judgments of the Superior Electoral Tribunal. It is concluded that the public interest is the effective exercise of the mandate, which should prevail over the individual interest of competing elective mandate.
\end{abstract}

Keywords: Functional Illiterate. Eligibility. Constitutional incompatibility.

\footnotetext{
${ }^{1}$ Professora de Direito Administrativo e de Direito Estadual e Municipal da Universidade Estadual do Sudoeste da Bahia (UESB). Mestre em Direito Administrativo e Ciência da Administração pela Universitádegli Studi di Bologna- Itália. Graduada em Direito pela Universidade Federal da Bahia. E-mail: marilzadonascimento@gmail.com.

2 Graduada em Direito pela Universidade Estadual do Sudoeste da Bahia. Assessora do Ministério Público Federal. E-mail: pabula_oliveira2@hotmail.com.
}

Página 41 Caderno de Ciências Sociais Aplicadas, Vitória da Conquista/BA, vol. 14, n 24, ano 14, p. 41-57, jul/dez 2017. 


\section{Introdução}

A Constituição Brasileira de 1988 concedeu legitimação eleitoral ativa aos analfabetos, mas vedou-lhes legitimação passiva. Há, no caso, regra constitucional que impede claramente pessoas não alfabetizadas de pleitearem cargos de chefia do Poder Executivo e de serem membros do Poder Legislativo. Entretanto, os parâmetros a serem adotados para se fazer cumprir a regra constitucional comportam sérias controvérsias, uma vez que o legislador infraconstitucional ainda não apresentou a definição de pessoa analfabeta para fins de elegibilidade.

O conceito de alfabetização é fornecido pela 'Pedagogia', ciência da educação e do ensino, cujo estudo demonstra não ser estanque essa definição, a qual sofre variações contextuais. No ano 1978, a Organização das Nações Unidas para a Educação, a Ciência e a Cultura (Unesco) definiu como alfabetizado o indivíduo que utiliza a leitura e a escrita em todas as atividades necessárias para o efetivo funcionamento de sua comunidade.

Com essa definição, a Unesco superou o entendimento firmado em 1951, o qual considerava alfabetizada a pessoa que sabia ler e escrever, com compreensão, um bilhete simples. Antes dessa época, na década de 1940, a Unesco considerava alfabetizada a pessoa capaz de decodificar os sinais gráficos e codificar os sons da língua.

A Justiça Eleitoral confere ao termo analfabetismo o sentido adotado pela Unesco na década de 1940, por admitir a elegibilidade do indivíduo que apenas seja capaz de firmar uma simples declaração, sem ulteriores exigências quanto à demonstração da capacidade de escrita e de leitura com compreensão. Assim, permite o exercício do ius honorum por aqueles que se enquadram no conceito de analfabeto funcional.

Percebe-se a estreita vinculação do analfabetismo como causa de inelegibilidade prevista na Constituição Brasileira de 1988 com a complexidade e a importância social e política das funções legislativas e executivas, as quais, por expressa determinação constitucional, requerem dos representantes do povo, nas esferas federal, estadual e municipal, as capacidades de apreensão e compreensão de conteúdos afetos a várias esferas do conhecimento, dificilmente alcançáveis sem o adequado letramento. ${ }^{3}$ Cita-se, por exemplo, o dever de promoção do desenvolvimento nacional, regional e local, a cargo dos governantes federais, estaduais e municipais, e as atuais demandas sociais

\footnotetext{
${ }_{3}^{3}$ Aqui, entende-se por portadora de adequado letramento a pessoa alfabetizada de acordo com a definição apresentada pela Unesco, anteriormente citada. Para a noção doutrinária de letramento vide MORTATTI (2007), SOARES (2004) e Ribeiro (1997).
}

Página 42 Caderno de Ciências Sociais Aplicadas, Vitória da Conquista/BA, vol. 14, n 24, ano 14, p. 41-57, jul/dez 2017. 
por políticas e ações públicas idôneas a produzirem resultados positivos nas áreas de segurança, saúde, educação, transporte, assistência e previdência social, habitação, geração de emprego e renda, abastecimento de água, energia, alimentos etc.

Essa abordagem pretende discutir a conformidade constitucional do sentido do termo analfabetismo albergado pela Justiça Eleitoral e sugerir a necessidade de que se promova uma revisão da sua posição, de modo a abranger a modalidade do analfabeto funcional.

Dada a imbricação entre os temas das (in)elegibilidades e dos direitos políticos, a estes será dedicado o primeiro tópico.

\section{Noção de direitos políticos}

Os direitos políticos surgiram a partir do fim da monarquia absolutista e do advento do Estado de Direito, quando a soberania popular suplantou o poder absoluto do rei e o povo assumiu a titularidade do poder do Estado por meio da representação política. No regime representativo, o povo delega seu poder a representantes escolhidos mediante processo eletivo para que esses o exerçam em seu nome.

Esses direitos se consubstanciam no conjunto de prerrogativas que permitem ao cidadão participar do governo e de suas decisões, da organização e do funcionamento do Estado. Nas palavras de José Afonso da Silva, “o direito democrático de participação do povo no governo, por seus representantes, acabara exigindo a formação de um conjunto de normas legais permanentes, que recebera a denominação de direitos políticos” (2010, p. 344).

A Constituição da República dedica um capítulo ao tema, no qual define que os direitos políticos, também denominados cívicos, consistem no conjunto de normas que disciplina o exercício da soberania popular, materializado pelo sufrágio universal, pelo voto direto e secreto, pelo plebiscito, pelo referendo e pela iniciativa popular. Tais direitos têm fundamento no princípio democrático, previsto no artigo $1^{\circ}$, parágrafo único, da lei maior, segundo o qual "Todo o poder emana do povo, que o exerce por meio de representantes eleitos ou diretamente, nos termos desta Constituição".

Entretanto, esses direitos somente são concedidos àqueles que a Constituição chama de povo, ou seja, aos habitantes do território nacional que preencham certos requisitos constitucionais e não indistintamente. No dizer de José Jairo Gomes, no sentido técnico jurídico constitucional, o povo é identificado como "o conjunto dos indivíduos a que se reconhece o direito de participar na formação

Página 43 Caderno de Ciências Sociais Aplicadas, Vitória da Conquista/BA, vol. 14, n 24, ano 14, p. 41-57, jul/dez 2017. 
da vontade estatal, elegendo ou sendo eleitos, ou seja, votando ou sendo votados, com vistas a ocupar cargos políticos-eletivos". (2010, p. 5).

O termo povo foi empregado pela Constituição Federal com o significado de cidadão e esse foi assumido pelo Direito Eleitoral, o qual considera cidadão a pessoa que se encontra no pleno exercício de seus direitos políticos, concepção restrita do termo cidadania, doravante referida como cidadania política. Em sentido amplo, como salienta Gomes (2010, p.5), a cidadania compreende todos os direitos civis, sociais, econômicos e políticos dos indivíduos, aos quais o Estado empresta proteção desde antes do nascimento.

A cidadania política é adquirida mediante alistamento eleitoral, quando o indivíduo se qualifica como eleitor. Contudo, embora titular dessa cidadania, o eleitor nem sempre pode exercer todos os direitos políticos porque a aquisição desses ocorre por etapas, com o preenchimento de condições que somente se incorporam ao cidadão de forma gradativa. O pleno exercício dos direitos políticos somente será adquirido após o cumprimento dos requisitos etários previstos no artigo $14, \int 3^{\circ}$, inciso VI da Constituição da República. José Afonso da Silva (2010) divide esses direitos em positivos e negativos. ${ }^{4}$

Os direitos politicos positivos representam o conjunto de normas que conferem aos cidadãos a prerrogativa de participarem do poder, dentre outros meios, através dos processos eleitorais, ao elegerem e serem eleito, e das ações propositivas e controladoras albergadas pelo ordenamento jurídico. ${ }^{5}$ Dada a especial proteção e topografia constitucional, esses direitos assumem caráter fundamental, cuja titularidade é conferida aos indivíduos isoladamente considerados e/ou à coletividade. ${ }^{6}$

A forma mais nítida de participação política é por intermédio do sufrágio ${ }^{7}$, o qual se apresenta em dois aspectos distintos: capacidade eleitoral ativa (direito de votar - alistabilidade) e capacidade

\footnotetext{
${ }^{4}$ Sarlet (2014) critica essa dicotomia por entender que os direitos políticos negativos não se consubstanciam direitos, mas restrições.

${ }^{5}$ José Afonso da Silva assim se expressa: Os direitos políticos positivos consistem no conjunto de normas que asseguram o direito subjetivo de participação no processo político e nos órgãos governamentais. Eles garantem a participação do povo no poder de dominação política por meio das diversas modalidades de sufrágio: direito de voto nas eleições, direito de elegibilidade (direito de ser votado), direito de voto nos plebiscitos e referendos, assim como por outros direitos de participação popular, como o direito de iniciativa popular, o direito de propor ação popular e o direito de organizar e de participar de partidos políticos (2009, p. 348).

${ }^{6}$ Vide Sarlet (2014, p. 668).

7 O sufrágio é, quanto à abrangência, classificado em universal ou restrito. Será universal quando não houver qualquer exigência de condição especial para o exercício do direito de voto. E restrito quando houver alguma exigência como, por exemplo, uma condição econômica (sufrágio censitário) ou intelectual (sufrágio capacitário). Destaca-se que os requisitos de fundo (nacionalidade, idade mínima etc.) ou de forma (alistamento eleitoral etc.) não retiram o caráter universal do sufrágio (MORAES, 2010).
}

Página 44 Caderno de Ciências Sociais Aplicadas, Vitória da Conquista/BA, vol. 14, n 24, ano 14, p. 41-57, jul/dez 2017. 
eleitoral passiva (direito de ser votado - elegibilidade) (MORAES, 2010). A primeira é pressuposto da segunda, haja vista que no direito brasileiro ninguém é elegível se não for previamente eleitor. ${ }^{8}$

A capacidade eleitoral ativa, conforme Djalma Pinto, "consiste na prerrogativa assegurada a cada cidadão de escolher, através do voto, os representantes que, durante certo período, conduzirão a chefia do Governo ou integrarão o Poder Legislativo" (2006, p. 140). Essa capacidade se adquire com o alistamento no órgão competente da Justiça Eleitoral, o qual verificará o cumprimento de determinados requisitos constitucionais e as condições legais necessárias à inscrição como eleitor: nacionalidade brasileira, idade mínima de dezesseis anos e não ser conscrito com o serviço militar obrigatório. Devidamente comprovada a inexistência de impedimentos ao alistamento eleitoral, o Tribunal Regional Eleitoral (TRE) habilitará o interessado como eleitor e promoverá a expedição do competente título.

No Brasil, ao contrário do que ocorre em outros países nos quais o voto é facultativo, a exemplo de Itália e França, a participação política para parcela dos nacionais é a um só tempo direito subjetivo e dever cívico juridicamente exigível pelo Estado, por serem obrigatórios o alistamento e o voto para os alfabetizados maiores de 18 e para os menores de 70. Entretanto, são facultativos para os analfabetos, os maiores de 70 anos, e para os que se situam na faixa etária dos maiores de 16 e menores de 18 anos.

A capacidade eleitoral passiva é a possibilidade de o cidadão, desde que preencha as condições de elegibilidade e em nenhuma das hipóteses de inelegibilidade incida, pleitear um mandato político mediante eleição popular, como bem sintetiza Djalma Pinto, "É o direito subjetivo público de ser votado" (2006, p. 151).

As condições de elegibilidade são os requisitos positivos impostos aos pleiteantes de cargos eletivos e apresentam variações, a depender da natureza ou do tipo do mandato almejado. O artigo 14, $\int 3^{\circ}$, da Constituição estabelece como condições de elegibilidade os seguintes requisitos: nacionalidade brasileira ou condição de português, a qual deve ser equiparada; pleno exercício dos direitos políticos; alistamento eleitoral; domicílio eleitoral na circunscrição do pleito; filiação partidária e idade mínima, essa variável entre 18 e 35 anos, de acordo com o cargo para o qual se queira eleger.

Os direitos politicos negativos consistem no conjunto de normas constitucionais que restringe a participação do cidadão no processo político e nos órgãos governamentais. Para José Afonso da Silva, são negativos exatamente porque negam ao cidadão o direito de eleger ou de ser eleito, ou de exercer

\footnotetext{
${ }^{8}$ Registra-se que o voto, além de um direito subjetivo, consiste em ato político que materializa o direito de sufrágio no plano prático. O Art. 14 da Constituição estabelece os caracteres do sufrágio e do voto; o primeiro, universal, e o segundo, secreto, obrigatório ou facultativo, direto e de valor igual para todos.
}

Página 45 Caderno de Ciências Sociais Aplicadas, Vitória da Conquista/BA, vol. 14, n 24, ano 14, p. 41-57, jul/dez 2017. 
atividade político-partidária, ou de exercer função política (SILVA, 2010, p. 379). Esses podem se consubstanciar hipóteses de inelegibilidade e causas de perda e de suspensão dos direitos políticos. ${ }^{9}$ Aqui, entretanto, se abordará apenas uma das causas de inelegibilidade, o analfabetismo.

\section{O analfabetismo como causa de inelegibilidade}

\section{Considerações gerais sobre inelegibilidades}

A inelegibilidade configura-se como condição obstativa ao exercício passivo da cidadania e traduz a ausência de capacidade de ser escolhido mandatário do povo. Swenson ensina que a inelegibilidade consiste na "impossibilidade legal de alguém pleitear seu registro como postulante a todos ou a alguns dos cargos eletivos" (apud BARROS, 2010, p. 252).

A Constituição prevê quatro causas de inelegibilidade, art. 14, parágrafos $4^{\circ}, 5^{\circ}, 6^{\circ}, 7^{\circ}$ e $9^{\circ}$, e a possibilidade do estabelecimento de outras, mediante lei complementar. ${ }^{10}$ Em 1990, foi editada a Lei Complementar nº 64/1990, conhecida como Lei das Inelegibilidades, com alterações introduzidas pelas leis complementares 81/1994 e 135/2010 (Lei da Ficha Limpa).

Segundo o artigo 14, $\mathbb{S} 9^{\circ}$ da Constituição, as inelegibilidades infraconstitucionais têm a finalidade de "proteger a probidade administrativa, a moralidade para exercício de mandato considerada a vida pregressa do candidato, e a normalidade e legitimidade das eleições contra a influência do poder econômico ou o abuso do exercício de função, cargo ou emprego na administração direta ou indireta".

As inelegibilidades podem ser classificadas, quanto à sua abrangência, em absolutas ou relativas. As primeiras são impedimentos para o exercício de qualquer cargo eletivo, pois se referem à determinada característica do postulante a candidato e somente podem ser estabelecidas pela própria Carta Magna, de modo taxativo. As segundas constituem-se restrições para determinados pleitos

\footnotetext{
9 SARLET (2014, p. 680) defende a impropriedade de se designar as causas de suspensão dos direitos políticos e de inelegibilidade de direitos políticos negativos porque aquelas não são direitos, mas restrições a esses.

${ }_{10}$ Art. 14. [...]

$\int 4^{\circ}$ São inelegíveis os inalistáveis e os analfabetos.

$\int 5^{\circ} \mathrm{O}$ presidente da República, os governadores de estado e do distrito federal, os prefeitos e quem os houver sucedido ou substituído no curso dos mandatos poderão ser reeleitos para um único período subsequente.

$\int 6^{\circ}$ Para concorrerem a outros cargos, os governadores de estado e do distrito federal e os prefeitos devem renunciar aos respectivos mandatos até seis meses antes do pleito.

$\int 7^{\circ}$ São inelegíveis, no território de jurisdição do titular, o cônjuge e os parentes consanguíneos ou afins, até o segundo grau ou por adoção, do Presidente da República, de Governador de Estado ou Território, do Distrito Federal, de Prefeito ou de quem os haja substituído dentro dos seis meses anteriores ao pleito, salvo se já titular de mandato eletivo e candidato à reeleição.
}

Página 46 Caderno de Ciências Sociais Aplicadas, Vitória da Conquista/BA, vol. 14, n 24, ano 14, p. 41-57, jul/dez 2017. 
eleitorais e certos mandatos, devido a situações especiais existentes em relação ao postulante a candidato no momento da eleição.

As inelegibilidades absolutas, de acordo com a Constituição Brasileira, compreendem os inalistáveis (estrangeiros e conscritos) e os analfabetos; as inelegibilidades relativas abrangem os motivos funcionais: casamento, parentesco e afinidade, militares e previsões de ordem legal.

Por fim, vale observar que inelegibilidades constitucionais podem ser arguidas a qualquer momento pelo interessado; as infraconstitucionais devem ser arguidas no prazo legal, sob pena de preclusão, salvo se supervenientes. ${ }^{11}$

\section{Breve noção de analfabetismo}

No Brasil, o analfabeto possui a capacidade eleitoral ativa ${ }^{12}$, mas, por determinação expressa do parágrafo $4^{\circ}$ do artigo 14 da Constituição, é-lhe vedado o exercício da capacidade eleitoral passiva. Essa inelegibilidade foi erigida no ordenamento jurídico para assegurar que os representantes do povo sejam portadores dos pré-requisitos indispensáveis à aquisição dos conhecimentos e das habilidades necessárias ao exercício das funções públicas das quais devem se desincumbir. Ante a omissão do legislador quanto à definição do analfabeto para fins de inelegibilidade passiva, essa missão compete aos órgãos do Poder Judiciário, os quais não deveriam se afastar do conceito fornecido pela ciência da educação e do ensino (Pedagogia), nem dos objetivos constitucionais.

A noção de pessoa alfabetizada apresentada pela ciência e acolhida pela Unesco vem acompanhando o desenvolvimento do conceito e contribuindo para a evolução social, política e econômica das várias sociedades.

Ao longo do processo, considerava-se como analfabetas apenas os analfabetos absolutos, ou seja, as pessoas que não sabiam decodificar as letras do alfabeto. No Brasil, até o censo demográfico de 1940 reputava-se alfabetizado quem sabia escrever o próprio nome.

Em 1958, a Unesco convocou vários especialistas em educação para instituírem certas regras escolares para fins de estatísticas, com o intuito de conhecer a alfabetização pelo mundo. $\mathrm{Na}$ ocasião, definiu-se que pessoa alfabetizada é aquela que sabe ler e escrever, com compreensão, um bilhete

\footnotetext{
${ }^{11}$ Nesse sentido são os ensinamentos, entre outros, de Almeida (2012, p. 94) e Sarlet (2014, p. 680).

12 Conforme observado pela doutrina, "Não foi com a CF/88 que os analfabetos adquiriram o direito de eleger seus representantes. Com a Emenda Constitucional no 25, de 15-5-1985, os analfabetos passaram a ter acesso, embora limitado, à cidadania. Puderam alistar-se como eleitores em qualquer eleição, e, nessa condição, passaram a exercer o direito de sufrágio, através do voto (MORAES, 2010, p. 231).
}

Página 47 Caderno de Ciências Sociais Aplicadas, Vitória da Conquista/BA, vol. 14, n 24, ano 14, p. 41-57, jul/dez 2017. 
simples; analfabeta, aquela que apenas assina o próprio nome; e semianalfabeta, aquela que sabe escrever e não sabe ler um pequeno texto, ou o contrário.

No censo de 1950, o recenseador brasileiro verificava o número de analfabetos no paíspor meio do denominado "critério do bilhete", o qual considerava alfabetizado aquele que respondia positivamente à pergunta: "sabe ler e escrever um bilhete simples?"

Em 1978, a Unesco propôs outra definição para a alfabetização e o termo letramento funcional (ou alfabetização funcional) começou a ser difundido pelo mundo. A nova recomendação dessa organização é citada por Magda Soares (2004, p. 73):

Uma pessoa é funcionalmente letrada, quando pode participar de todas aquelas atividades nas quais o letramento é necessário para o efetivo funcionamento de seu grupo e comunidade e, também, para capacitá-la a continuar usando a leitura, a escrita e o cálculo para seu desenvolvimento e o de sua comunidade.

Percebe-se que essa nova definição não se limita a verificar a capacidade de usar a leitura e a escrita em apenas uma prática social (ler e escrever um simples bilhete), mas em todas aquelas necessárias para o adequado funcionamento do indivíduo no seu contexto social, cultural, político e econômico. $^{13}$

O conceito de analfabeto funcional, como se procurará demonstrar, apresenta critérios definidores da condição de pessoa alfabetizada, salvo melhor juízo, mais compatíveis com a finalidade constitucional do que os admitidos pela Justiça Eleitoral.

\section{A definição de pessoa alfabetizada para a Justiça Eleitoral}

Para concorrer a um cargo político eletivo, o postulante a candidato, também denominado de pré-candidato e de candidato a candidato, deve fazer o pedido de registro de candidatura na Justiça Eleitoral $^{14}$, acompanhado de documentos que comprovem os requisitos de elegibilidade e o não enquadramento em uma das hipóteses de inelegibilidade.

\footnotetext{
${ }_{13}$ Para designar esse novo fenômeno surgiu o termo letramento, o qual, segundo Magda Soares (2004, p. 18), significa "o resultado da ação de ensinar ou de aprender a ler e a escrever: o estado ou condição que adquire um grupo social ou um indivíduo como consequência de ter-se apropriado da escrita".

14 A primeira opção do formulário de requerimento de candidatura consiste na pergunta "lê e escreve?" Levantamento apresentado pelo TSE revela que 254 (duzentos e cinquenta e quatro) candidatos às eleições do ano 2014 declararam que sabiam apenas ler e escrever, o que representa $1 \%$ do total de 24.900 (vinte e quatro mil e novecentos) candidatos.
}

Página 48 Caderno de Ciências Sociais Aplicadas, Vitória da Conquista/BA, vol. 14, n 24, ano 14, p. 41-57, jul/dez 2017. 


\section{- Cadernos de Ciénclas SOCIAIS APLICADAS}

A comprovação da condição de alfabetizado, perante a Justiça Eleitoral, estatuída para as eleições de 2016, manteve-se substancialmente inalterada em relação aos pleitos anteriores. A Resolução do TSE no 23.465/2016exige o comprovante de escolaridade no Artigo 27, inciso IV. Entretanto, prevê no parágrafo 11que a ausência desse "poderá ser suprida por declaração de próprio punho, podendo a exigência de alfabetização do candidato ser comprovada por outros meios, desde que individual e reservadamente".

Conforme será demonstrado, o TSE recomenda em acórdãos eleitorais, caso não haja prova de escolaridade, a aplicação de um teste de alfabetização, o qual deve considerar alfabetizado aquele que minimamente possui a capacidade de ler e de escrever uma breve exposição de fatos relativos à vida cotidiana, ainda que com grande dificuldade e sem compreensão.

Esse teste de alfabetização é conhecido no meio eleitoral como "teste do bilhete", em alusão ao critério sugerido pela Unesco, em 1958, para verificar o número de analfabetos e de alfabetizados mundialmente. Entretanto, ambos os critérios não se confundem, pois o conceito adotado pela Unesco, naquele ano, exigia a compreensão da leitura para um indivíduo ser considerado alfabetizado, conforme mencionado no tópico anterior.

Quanto à elegibilidade do semianalfabeto, o TSE possui entendimento pacificado acerca do tema, no sentido de que é possível a candidatura daquele para qualquer cargo eletivo, sob a justificativa de ser impossível a aplicação da regra de inelegibilidade dos analfabetos para os semianalfabetos. Nesse diapasão, o seguinte aresto:

RECURSO ELEITORAL. REGISTRO DE CANDIDATURA. INDEFERIMENTO. INELEGIBILIDADE. APLICAÇ̃̃O DE TESTE DE ALFABETIZAÇÃO. CONDIÇÃO DE SEMIANALFABETO DEMONSTRADA NOS AUTOS. PRECEDENTES DESTE TRIBUNAL E DO TSE. 1. Por se tratar a inelegibilidade de uma restrição a um direito político do cidadão, o de ser votado, o art. 14, $\ 4^{\circ}$ da Constituição Federal deve ser interpretado restritivamente. 2. A Constituição Federal de 1988, ao cominar a inelegibilidade aos analfabetos, não trouxe uma definição para estes, o que também não foi feito pelas leis infraconstitucionais. 3 . O TSE, ao tentar preencher a lacuna do ordenamento jurídico acerca de quem seria analfabeto, para fins de inelegibilidade, deixou evidente sua preocupação com o exercício do direito político passivo do cidadão de ser eleito. 4. Quando demonstrada, nos documentos acostados aos autos, a condição de semianalfabeto do candidato, a ele não pode ser cominada a inelegibilidade 5. Recurso conhecido e provido (MARANHÃO. Tribunal Regional Eleitoral. Recurso Especial Eleitoral n. 3105. Relator: Jorge Rachid Mubarack Maluf, São Luís, 31 agosto, 2003).

Página 49 Caderno de Ciências Sociais Aplicadas, Vitória da Conquista/BA, vol. 14, n 24, ano 14, p. 41-57, jul/dez 2017. 
Pela análise da decisão acima, nota-se que o TSE adota a interpretação restritiva das inelegibilidades, por essas serem condições obstativas ao exercício do direito político de ser eleito, sendo esse o motivo do afastamento de critérios mais rigorosos para a aferição da condição de alfabetizado do postulante a candidato. É ilustrativo o seguinte Acórdão:

Inelegibilidade. Analfabetismo. 1. A jurisprudência do TSE é pacífica no sentido de que as restrições que geram as inelegibilidades são de legalidade estrita, sendo vedada a interpretação extensiva. 2. Essa orientação se aplica, inclusive, quanto à configuração da inelegibilidade do art. 14, \ $4^{\circ}$, da Constituição Federal, devendo exigir-se do candidato apenas que ele saiba ler e escrever minimamente, de modo que se possa evidenciar eventual incapacidade absoluta de incompreensão e expressão da língua. 3. Não é possível impor restrição de elegibilidade, por meio da utilização de critérios rigorosos para a aferição de alfabetismo. 4. A jurisprudência do TSE é no sentido de que "a Carteira Nacional de Habilitação para dirigir gera a presunção da escolaridade necessária ao deferimento do registro de candidatura" (Agravo Regimental no Recurso Ordinário no 4459-25, rel. Min. Marco Aurélio, de 7.6.2011). Agravo regimental não provido (BRASIL. Tribunal Superior Eleitoral. Recurso Especial Eleitoral n. 6616. Relator: Min. Arnaldo Versiani Leite Soares, Brasilia, 18 out. 2012).

Emblemática é a decisão unânime do Tribunal Regional Eleitoral de São Paulo, a qual deferiu o registro de candidatura a candidata que, não tendo comprovado a escolaridade, apresentou declaração de próprio punho às vésperas do julgamento do recurso. Decisão desse jaez pode não somente permitir a candidatura de analfabetos funcionais, mas, inclusive, incentivar possíveis fraudes, à medida que pode favorecer a fuga ao teste de alfabetização:

RECURSO ELEITORAL EM REGISTRO DE CANDIDATURA. ELEIÇÕES 2016. Verificada causa de inelegibilidade. Artigo $14, \rrbracket 4^{\circ}$ da Constituição Federal. Ausência de comprovante de escolaridade ou de declaração de $\backslash$ próprio punho do interessado. Apresentação às vésperas do julgamento. RECURSO PROVIDO para deferir o registro. (Recurso Eleitoral $\mathrm{n}^{\circ}$ 21445. Relator: Juiz Silmar Fernandes, São Paulo, 26.09.2016) (grifos nossos)

Assim, depreende-se que o conceito de analfabeto adotado pela Justiça Eleitoral abrange apenas o analfabeto absoluto, por considerar inapto ao exercício de cargo político eletivo apenas aquele que, nos termos do Acórdão acima, não “saiba ler e escrever minimamente". Esse critério difere do conceito de analfabeto funcional adotado pela Unesco, no ano 1978 e, o que é mais grave, muito se afasta da pretensão constitucional, por proteger o interesse individual de postulantes a candidatos e dos partidos, em detrimento dos interesses sociais.

Página 50 Caderno de Ciências Sociais Aplicadas, Vitória da Conquista/BA, vol. 14, n 24, ano 14, p. 41-57, jul/dez 2017. 
O analfabetismo funcional, salvo melhor juízo, encerra a presunção absoluta de inaptidão para o exercício de qualquer cargo público. A Constituição, no art. 37, II, precisa que "a investidura em cargos ou empregos públicos depende da aprovação prévia em concurso público de provas ou de provas e títulos, de acordo com a natureza e a complexidade do cargo ou emprego (...)". Observa-se que, mesmo os concursos públicos para atividades braçais, como a limpeza pública, têm exigido, no mínimo, a comprovação do ensino fundamental. Ora, se a demonstração de escolaridade mínima é necessária até mesmo para os exercentes de funções executivas de baixa ou de nenhuma complexidade, com muito maior razão para os responsáveis pelas mais importantes e complexas decisões de governo, como são os chefes do Executivo e os membros do Legislativos, no âmbito federal, estadual e municipal.

Sendo assim, não parece ser razoável os julgadores, sobretudo os das instâncias superiores, ${ }^{15}$ demonstrarem maior "preocupação com o exercício do direito político passivo do cidadão de ser eleito" do que com o direito do povo de ter representantes políticos habilitados para o exercício das próprias funções.

\section{A incongruência do conceito de pessoa alfabetizada da Justiça Eleitoral com as funções constitucionais dos representantes públicos}

A interpretação constitucional, considerada a principal interpretação jurídica ${ }^{16}$, envolve a necessidade de se buscar o verdadeiro conteúdo semântico dos termos linguísticos que formam as normas constitucionais. Antes de tudo, deve-se buscar a interpretação que melhor se conforma ao desiderato da Constituição. Para tal mister foram forjados pela doutrina e pela jurisprudência vários princípios interpretativos, o da unidade da constituição dentre esses, em que as normas constitucionais não devem ser interpretadas isoladamente, mas em conformidade com o seu inteiro teor. ${ }^{17}$

Ao se analisar a Carta da República, vê-se que o constituinte de 1988 teve preocupação especial com a dignidade humana (art. art. $1^{\circ}$, III), com a garantia de direitos individuais (art. $5^{\circ}$ ) e sociais (art.

\footnotetext{
15 Merece ser destacada a postura de alguns juízes de primeiro grau e de alguns tribunais regionais eleitorais, como, por exemplo, o TRE do Ceará e do Rio Grande do Norte, que não obstante o mencionado entendimento do TSE, com base no teste de alfabetização, têm indeferido o registro de candidatura aos semianalfabetos.

16 "A interpretação jurídica consiste na atividade de revelar ou atribuir sentido a textos ou outros elementos normativos (como princípios implícitos, costumes, precedentes), notadamente para o fim de solucionar problemas. Trata-se de uma atividade intelectual informada por métodos, técnicas e parâmetros que procuram dar-lhe legitimidade, racionalidade e controlabilidade. A aplicação de uma norma jurídica é o momento final do processo interpretativo, sua incidência sobre os fatos relevantes. $\mathrm{Na}$ aplicação se dá a conversão da disposição abstrata em uma regra concreta, com a pretensão de conformar a realidade ao Direito, o ser ao dever ser. É nesse momento que a norma jurídica se transforma em norma de decisão." (BARROSO, 2009, p. 269-270).

${ }^{17}$ Sobre interpretação Constitucional consultar, dentre outros, BARROSO (2009); MENDES (2010) e SARLET (2014).
}

Página 51 Caderno de Ciências Sociais Aplicadas, Vitória da Conquista/BA, vol. 14, n 24, ano 14, p. 41-57, jul/dez 2017. 
$6^{\circ}$ ) e deu especial proteção ao princípio da igualdade quando vetou expressamente, no art. $5^{\circ}$, qualquer tipo de discriminação. Se a igualdade é um valor e direito fundamental garantido aos brasileiros, especificamente em relação ao dispositivo que nega ao analfabeto a capacidade eleitoral passiva, entende-se que o constituinte não teve escopo meramente discriminatório, mas funcional, uma vez que letramento, obviamente, não é garantia de bom desempenho de mandatos políticos, entretanto, sua ausência é presumivelmente impeditiva; haja vista remontarem as funções constitucionais que lhes são inerentes ao domínio da leitura. ${ }^{18}$

Sabe-se que o Estado de Direito se respalda no império da lei, significando que encontra-se, em todas as suas dimensões e ações sujeito aos parâmetros da legalidade.

Em consonância com esta característica, revelar-se-ia inconcebível incoerência do ordenamento jurídico constitucional permitir-se que a sociedade fosse dirigida por quem, apesar de identificar e de escrever algumas palavras, não possui o letramento necessário para ler e compreender o verdadeiro sentido e alcance das leis que está obrigado a produzir, fiscalizar e controlar a execução (membros do Legislativo) ou a aplicá-las e/ou coordenar-lhes a aplicação (Chefe do Executivo).Quando alguém é solicitado a ler a lei, assevera Fábio Alves, não está sendo chamado apenas para “decodificar sinais de um texto normativo, mas para adotar determinados comportamentos ou assumir certas responsabilidades. A leitura, portanto, tem ligação direta com os que se propõem a fazer ou a cumprir a lei" (2001, p. 69).

Apesar da notória importância de os representantes políticos possuírem as habilidades adquiridas com o letramento, a legislação não exige qualquer qualificação específica para uma pessoa se candidatar a um cargo eletivo, nem os Tribunais Eleitorais adotaram critérios interpretativos aptos a evitarem que analfabetos funcionais possam ocupá-lo, mesmo que o exercício desse seja considerado de alta complexidade pela própria Constituição da República. Por outro lado, para o exercício dos demais cargos públicos, mesmo aqueles de menor complexidade, há exigência de um mínimo de escolaridade ou de embasamento teórico e de conhecimento técnico para o exercício da função. A esse respeito, Djalma Pinto aponta:

\footnotetext{
${ }^{18}$ As competências da União, estados, distrito federal e municípios estão previstas nos artigos 21-32 e as funções que competem aos membros do Poder Legislativo, por determinação expressa ou simetria, estão previstas e/ou compreendidas nos artigos 44-75 e do Chefe do Executivo, nos artigos 76-86 da Constituição Federal.
}

Página 52 Caderno de Ciências Sociais Aplicadas, Vitória da Conquista/BA, vol. 14, n 24, ano 14, p. 41-57, jul/dez 2017. 
Há uma curiosidade, a propósito deste tema, que chega a intrigar largo segmento da sociedade. Para exercer a função de gari, responsável pela coleta do lixo, exige a Administração que o cidadão se submeta a exame para aferição de sua escolaridade. Ninguém, em princípio, pode ser servidor público sem prévia habilitação em concurso (art. 37, II, da CF). Tal exigência, porém, não atinge os agentes políticos. Para postular qualquer cargo eletivo é irrelevante o grau de escolaridade do candidato. A única restrição imposta pela Constituição dirige-se aos analfabetos (2006, p. 263-264).

É válido ressaltar que há acentuada incoerência nesse raciocínio: se alguém não pode ser considerado apto para desempenhar a função de servidor público, como poderia ter habilidade para tornar-se representante político, uma vez que, nesse posto, caberia a ele a definição, a direção e a consecução das finalidades do Estado, atividades intrinsecamente complexas?

Diferentemente do que ocorre no Brasil, onde não se impõe qualquer grau de escolaridade para os representantes políticos, a Constituição Política da República do Chile exige que os deputados (Art.44) e senadores (Art.46) tenham cursado, no mínimo, o ensino médio ou equivalente.

Verifica-se que o cidadão chileno, para candidatar-se a tais cargos, precisa não apenas saber ler e escrever, mas ter completado o ensino médio, nível escolar no qual a Lei no 18.962 , denominada Lei da Educação do Chile, presume que se adquiram as habilidades necessárias para o domínio da leitura e da escrita, além de outros conhecimentos científicos (art. 13, b). Essa lei prevê que o controle simples da leitura e da escrita é adquirido com a conclusão do ensino básico (art. 11, a) (ALVES, 2001) ${ }^{19}$.

Voltando o foco de abordagem para o que ocorre no Brasil, diante da vedação constitucional para a elegibilidade do analfabeto e da inconsistência do conceito de pessoa alfabetizada oferecido pela ciência e pela Unesco, se o postulante a candidato não demonstrar domínio eficiente da leitura e da escrita nas práticas sociais que envolvem o exercício do mandato eletivo pretendido, falece-lhe direito de candidatar-se à representação do povo por lhe faltarem os requisitos minimamente exigidos para este fim. Não há, pois, que se falar em violação ao direito subjetivo, por esse inexistir, nesse caso.

Como expôs Adriano Costa (apud RÉ, 2012, p. 111), o direito a ser eleito somente é adquirido com o deferimento do pedido de registro de candidatura; antes disso, o postulante a candidato é inelegível, situação que se repete após a apuração dos votos até o registro de nova candidatura. Demanda, pois, o preenchimento de requisitos constitucionais, dentre os quais o de ser alfabetizado. Atualmente, de acordo com a Unesco e com a Pedagogia, são reconhecidos como portadores dessa

\footnotetext{
${ }^{19}$ No Brasil, essa mesma presunção se tem com a conclusão do ensino fundamental, o qual, de acordo com o art. 32, II da Lei no 9.394/96, com redação dada pela Lei 11.274/2006, tem por objetivo, dentre outros, "o desenvolvimento da capacidade de aprender, tendo como meios básicos o pleno domínio da leitura, da escrita e do cálculo".
}

Página 53 Caderno de Ciências Sociais Aplicadas, Vitória da Conquista/BA, vol. 14, n 24, ano 14, p. 41-57, jul/dez 2017. 
condição apenas os indivíduos que apreenderam a arte da escrita e desenvolveram-se na compreensão da leitura.

Sabe-se que diante do choque de princípios fundamentais, a solução se obtém mediante a ponderação de todos os valores protegidos, prevalecendo aquele que melhor atende à proteção do bem comum. Parece indubitável que, a partir da interpretação sistemática da Constituição, entre o aparente direito de eleição do "semianalfabeto" e o direito do povo ao governante capaz de se desincumbir adequadamente de suas funções deva prevalecer esse último. Se há acinte na condição de o parlamentar semianalfabeto não corresponder aos ditames do cargo, também o há por parte daqueles que o elegeram, ao votarem pessoas presumivelmente incompetentes, por ironia ou por atitude blasé, conscientes da inadequação dessas ao cargo que lhes conferem.

Assim, por não exigir do postulante a candidato a demonstração inequívoca de suas habilidades de escrita e de leitura e aceitar o registro de candidatura de analfabetos funcionais, salvo melhor juízo, a Justiça Eleitoral se afasta do objetivo constitucional assumido por meio da restrição em comento. Mesmo porque essa prerrogativa tem gerado graves aberrações, consistentes na garantia de elegibilidade a muitos que usufruem das benesses dos cargos, sem contrapartida para a sociedade, porquanto reconhecidamente inaptos para o exercício de qualquer função pública.

\section{Considerações finais}

A Constituição, no art. $18, \sqrt{ } 4^{\circ}$, veda o exercício do direito de ser eleito ao analfabeto, porém, tampouco menciona o legislador o que se entende por analfabetismo. Essa omissão normativa tem gerado dificuldade de aplicação do dispositivo frente às diversas concepções do termo.

A pesquisa demonstrou que a interpretação dos Tribunais Eleitorais sobre a inelegibilidade do analfabeto ainda gera perplexidades, porquanto distanciada tanto da ciência quanto dos objetivos constitucionais razoavelmente presumíveis dessa previsão normativa.

Contudo, a jurisprudência dos Tribunais Eleitorais considera analfabeto, para fins de inelegibilidade, apenas o analfabeto absoluto, sem abarcar o analfabeto funcional e o semianalfabeto. $\mathrm{O}$ Tribunal Superior Eleitoral entende que a interpretação das inelegibilidades deve ser restritiva porque tem por objeto o direito subjetivo de ser eleito. Todavia, em relação ao analfabeto, essa fundamentação não se sustenta em face da definição científica de pessoa alfabetizada e do conjunto das competências públicas atribuídas aos exercentes dos cargos eletivos.

Página 54 Caderno de Ciências Sociais Aplicadas, Vitória da Conquista/BA, vol. 14, n 24, ano 14, p. 41-57, jul/dez 2017. 
A definição de analfabeto, para fins de aplicação do artigo $14, \int 4^{\circ}$, da Constituição, urge ser confrontada porque a predominância absoluta do direito de ser eleito tem gerado graves aberrações na garantia de elegibilidade a analfabetos funcionais, pessoas reconhecidamente inaptas para o exercício de qualquer função pública, ante a carência de competências e de habilidades apenas facultadas pelo domínio da escrita e da leitura críticas.

Julga-se que não são os interesses individuais dos postulantes a representantes e dos partidos políticos que devem prevalecer, mas o direito do povo em ser representado politicamente por um governante apto ao desempenho das funções inerentes ao exercício do cargo.

Sabe-se que o letramento ou mesmo o alto grau de escolaridade não constituem garantia de boa governança, a qual exige, além de habilidades de ordem técnica e política, atributos de caráter, prática da ética e espírito cívico e republicano. Entretanto, a mudança do sentido do termo analfabetismo, na interpretação da Justiça Eleitoral, de forma a abranger o analfabeto funcional, contribuiria para a gradativa atenuação do clássico e desastroso defeito da democracia, apontado por Platão e mencionado por Eduardo Bittar: “a entrega da coisa pública nas mãos de cidadãos despreparados para o exercício de suas funções” Bittar (2005, p. 61).

É inconteste que a ocupação de qualquer cargo político possui como condição sine qua non a alfabetização do aspirante e essa, pelas razões expostas neste trabalho, não pode ser outra que a funcional. Enquanto perdurar a omissão do legislador quanto a definição de pessoa alfabetizada para fins eleitorais, cabe ao Judiciário Eleitoral e ao Supremo Tribunal Federal contribuírem para o aprimoramento do processo político e social por meio da conformação da interpretação do termo analfabetismo aos objetivos constitucionais. Tal mudança de postura imprimirá maior proteção aos valores e aos direitos societários fundamentais, à medida que servirá como ponto de partida para a melhor qualificação dos aspirantes aos cargos públicos eletivos.

Ademais, anotou-se que a interpretação da Justiça Eleitoral sobre o tema se afasta do objetivo constitucional, em razão de os analfabetos funcionais não serem capazes de produzir, ler e compreender atos legislativos e administrativos inerentes ao desempenho das funções públicas essenciais ao funcionamento do Estado e ao atendimento das necessidades da população. Portanto, eles se enquadram na vedação inserta no art. $14, \int 4^{\circ}$ da Constituição. Outrossim, apontamos que o interesse individual de ser eleito não deve prevalecer ou confrontar-se com os demais interesses de haver representantes com nível de instrução minimamente necessário à compreensão e ao efetivo desenvolvimento das atividades inerentes aos seus misteres.

Página 55 Caderno de Ciências Sociais Aplicadas, Vitória da Conquista/BA, vol. 14, n 24, ano 14, p. 41-57, jul/dez 2017. 
Assim, restrições à elegibilidade não caracterizam violação ao direito de ser eleito, esse somente é adquirido com o deferimento do pedido de registro de candidatura. Esse apontamento desmitifica a justificativa dos Tribunais Eleitorais, acima mencionada, sobre o reconhecimento da elegibilidade dos semianalfabetos e dos analfabetos funcionais, por lhes faltarem as habilidades da escrita e da leitura indispensáveis ao efetivo desempenho das funções inerentes aos cargos políticos para os quais forem escolhidos pelos eleitores.

A argumentação apresentada reitera a necessidade de se ampliar o sentido do termo alfabetizado - adotado pela Justiça Eleitoral - em direção ao conceito adotado pela Pedagogia e pela Unesco, a partir de 1978, como exigência da proteção do interesse público sobre quaisquer outras considerações. Ora, se essa concepção de alfabetização, como mencionado anteriormente, aplica-se ao detentor de cargos públicos administrativos, com maior razão aos políticos, cujos ocupantes são responsáveis pelas mais relevantes funções públicas seja no âmbito nacional, estadual ou municipal. Consequentemente, requerimentos sociais dessa magnitude invalidam a restrição da alfabetização aos rudimentos da leitura e da escrita, em virtude de não se poder conceber competências básicas como simples ou rudimentares.

\section{Referências}

ALMEIDA, Roberto Moreira. Alistabilidade e elegibilidade dos indígenas no ordenamento jurídico brasileiro. In: RAMOS, André (coord.). Temas de Direito Eleitoral no Século XXI. Brasília: ESMPU, 2012, p. 69-107.

ALVES, Fábio.O teste de alfabetização do pré-candidato a cargo eletivo: a concretização do art. 14, $\int$ 4. ${ }^{\circ}$, da Constituição Federal. Revista de informação legislativa, Brasília. v. 38, n. 152, p. 67-78, out./dez. 2001.

BARROS, Francisco Dirceu. Direito Eleitoral: teoria, jurisprudência e mais de 1.000 questões comentadas. 9. ed. Rio de Janeiro: Elsevier, 2010.

BARroso, Luís Roberto. Curso de Direito Constitucional Contemporâneo: os conceitos fundamentais e a construção do novo modelo. São Paulo: Saraiva, 2009.

BITTAR, Eduardo. Curso de filosofia política. 2. ed. São Paulo: Atlas, 2005.

BRASIL. Constituição da República Federativa do Brasil (1988):promulgada em 5 de outubro de 1988. São Paulo: Saraiva, 2010.

. Tribunal Superior Eleitoral. Recurso Especial Eleitoral n. 6.616. Relator: Min. Arnaldo

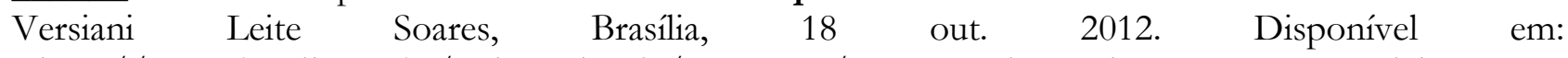

$<\underline{\text { http://tse.jusbrasil.com.br/jurisprudencia/23317621/agravo-regimental-em-recurso-especial- }}$ eleitoral-agr-respe-6616-go-tse> Acesso em: 15 out. 2014.

Página 56 Caderno de Ciências Sociais Aplicadas, Vitória da Conquista/BA, vol. 14, nº 24, ano 14, p. 41-57, jul/dez 2017. 
. Tribunal Superior Eleitoral. Resolução n.23.455, de 3 de dezembro de 2015. Dispõe sobre a escolha e o registro de candidatos nas eleições municipais de 2016. Disponível em: <http://www.justicaeleitoral.jus.br/arquivos/tse-resolucao-23-455-instrucao-53-535-versaoconsolidada> Acesso em: 31 jul. 2017.

CHILE. Constitucion Politica de la Republica de Chile (1980). Con modificaciones aprobadas en el plebiscito de 30 de julio de 1989 incorporadas al texto. Disponível em: < http://www.constitution.org/cons/chile.htm> Acesso em: 11 nov. 2014.

GOMES, José Jairo. Direito Eleitoral. 5. ed. Belo Horizonte: Del Rey, 2010.

MARANHÃO. Tribunal Regional Eleitoral.Recurso Eleitoral n. 3105. Relator: Jorge Rachid Mubarack Maluf, São Luís, 31 agost. 2003. Disponível em: < http://trema.jusbrasil.com.br/jurisprudencia/23164625/recurso-eleitoral-re-3105-ma-trema $>$ Acesso em: 15 out. 2014.

MENDES, Gilmar; COELHO, Inocêncio; BRANCO, Paulo. Curso de Direito Constitucional.5. ed. São Paulo: Saraiva, 2010.

MORAES, Alexandre de. Direito Constitucional Administrativo. 3. ed. São Paulo: Atlas, 2006.

Direito Constitucional. 26. ed. São Paulo: Atlas, 2010.

MORTATTI, Maria. Letrar é preciso, alfabetizar não basta... mais? In: SCHOLZE, Lia; Rösing, Tania (orgs.). Teorias e práticas de letramento. Brasília: INEP, 2007, p. 155-168.

PINTO, Djalma. Direito eleitoral: improbidade administrativa e responsabilidade fiscal. 3. ed. São Paulo: Atlas, 2006.

RÉ, Mônica. A ficha limpa e a inelegibilidade - avanço histórico e democrático. In: RAMOS, André (coordenador). Temas de Direito Eleitoral no Século XXI. Brasília: ESMPU, 2012, p. 109-131.

RIBEIRO, Vera. Alfabetismo funcional: referências conceituais e metodológicas para a pesquisa. Educação \& Sociedade, Campinas. v. 18, n. 60, p. 144- 158, dez.1997.

SÃO PAULO. Tribunal Regional Eleitoral. Recurso Eleitoral n. 21445. Relator: Juiz Silmar Fernandes, São Paulo, 26.09.2016.Disponível em:http://www.tre-sp.jus.br/jurisprudencia/pesquisa-dejurisprudencia/jurisprudencia. Acesso em 01.08.2017.

SARLET, Ingo Wolfgang. O sistema Constitucional Brasileiro. In: SARLET, Ingo Wolfgan; MARINONI, Luiz Guilherme; MITIDIERO, Daniel. Curso de Direito Constitucional. São Paulo: Revista dos Tribunais, 2014, p. 363-701.

SILVA, José Afonso da. Curso de Direito Constitucional Positivo. 33. ed. São Paulo: Malheiros Editores, 2010.

SOARES, Magda. Letramento: Um tema em três gêneros. 2. ed. Belo Horizonte: Autêntica, 2004. 